\title{
Академическое предпринимательство в свете влияния основных трендов развития системы образования в России 1
}

\author{
Айрат Измайлов \\ Самарский государственный экономический университет, Самара, Россия
}

Информация о статье

Поступила в редакичию:

27.09.2018

Принята к опубликованию:

04.04.2019

УДК 334

JEL I25; L31

\section{Ключевые слова:}

академическое предпринимательство, предпринимательство, предпринимательский университет, мегатренды, тренды, тенденции, система образования

\section{Keywords:}

academic entrepreneurship; entrepreneurship; entrepreneurial university; megatrends; trends; tendencies, education system

\begin{abstract}
Аннотация
В статье рассматривается влияние важнейших мировых мегатрендов и вытекающих из них трендов развития системь образования на академическое предпринимательство. Установлено, что тренды, представленные в работе, несут в себе потенциальные изменения, касаюшиеся всех сфер жизни, в том числе образования и академического предпринимательства. Углубленное изучение трендов и реакций общества на данные тренды могут позволить разработать инструменты гибкой адаптации к меняющуимся условиям. Предложены направления дальнейиих исследований.
\end{abstract}

\section{Academic Entrepreneurship in the Light of Impact of the Main Trends of Development of the Educational System in Russia}

Izmailov Ayrat

\section{Abstract}

Academic entrepreneurship is becoming an increasingly relevant area of research at the present stage of social development. This state of affairs is primarily due to the development of the knowledge economy and the increase in the commercial value of intellectual (information) products. Academic entrepreneurship, in the light of the main trends of the Russian education system development impact, assumes a certain development vector, which primarily proceed from such trends in the development of the education system and science as a whole as: informatization, gamification, individualization, changing of consumers economic preferences and a number of others.

Therefore, the objective of the work is to study the main directions and trends of the scientific knowledge commercialization in Russia and abroad in the light of the main trends and the trends in the system of education and science impact.

\footnotetext{
1 Исследование выполнено в рамках государственного задания Министерства образования и науки РФ № 26.940.2017/ПЧ, проект «Управление изменениями в системе выстего образования на основе концепции устойчивого развития и согласования интересов» DOI: https://dx.doi.org/10.24866/2311-2271/2019-4/103-109
} 
The trends described in the article cause potential changes relating to all spheres of life, including academic entrepreneurship. A considerable research of the trends and the society reactions to these trends may allow us to work out the tools for managing the academic entrepreneurship development.

\section{Введение}

Академическое предпринимательство на современном этапе общественного развития становится все более актуальным направлением исследований. Это обусловлено, прежде всего, развитием экономики знаний и повышением коммерческой ценности интеллектуальной (информационной) продукции $[1$, 2]. Академическое предпринимательство, в свете влияния основных трендов развития системы образования в России приобретает определенный вектор развития, отталкивающийся от таких тенденций развития системы образования и науки, как информатизация, геймификация, индивидуализация, изменение экономических предпочтений потребителей и пр.

В связи с этим, целью работы является исследование основных направлений и трендов коммерциализации научных знаний в России и за рубежом в свете влияния основных трендов и тенденций в системе образования и науки.

Теоретической основой исследования послужили труды таких экономистов, как С.И. Ашмарина, Л.Н., Бабак, В.Г. Белкин, Е.А. Кандрашина, В.Г. Кречетников, И.Г. Филаткина, Е.В. Хегай, М. Abreu, H. Bathelt, G. Nabi, A. Sikula, M.S. Wood, D.M. Weckowska, R. Fairchild, L. Mindeli, J. Zhang, G. Lazarev.

\section{Методология исследования}

В исследовании использован метод восхождения от абстрактного к конкретному заключающийся в условном расчленении объекта исследования, описании его свойств при помощи множества понятий и характеристик. Так же использован метод анализа.

\section{Обсуждение полученных результатов}

Экономический аспект системы образования - это не только воспроизводство и обучение трудовых ресурсов средней и высшей квалификации, но и создание новых знаний, которые в последствии могут быть коммерциализированы. В общем и целом, коммерциализация новых знаний и инноваций называется академическим предпринимательством. М. Abreu, V. Grinevich рассматривают академическое предпринимательство в контексте трех видов деятельности: формальная коммерческая, неформальная коммерческая и некоммерческие виды деятельности [3, 4]. В работах S. Nabi и J. Zhang академическое предпринимательство представлено как один из рычагов повышения конкурентоспособности страны и региона $[5,6]$. Однако исследователи A. Sikula и M. Wood сужают потенциал академического предпринимательства до возможности удовлетворения потребностей вуза или отдельного академического предпринимателя $[6,7,8]$.

Мы солидарны с позицией ученого $\mathrm{H}$. Bathelt, научная позиция которого такова, что некоммерческая деятельность академических предпринимателей основывается на незащищенных знаниях и осуществляется для повышения социального благополучия академического предпринимателя. К данному виду деятельности могут быть отнесены предоставление неофициального совета, проведение публичных лекций, организация выставок и издание книг для широкой аудитории, неофициальные консультации и т.д. $[9,10]$. 
Благосостояние современного общества, в первую очередь, зависит от сложных факторов его развития, к формированию которых это общество имеет самое непосредственное отношение. Речь идет о таких факторах, как наука, образование, культура, технология. Однако, на них воздействуют элементы окружающей среды, тем самым внося изменения. Анализ показал, что на сегодняшний день можно выделить целый спектр мегатрендов, оказывающих влияние на все мировое сообщество, в том числе, на систему образования. Среди таких мегатрендов можно выделить следующие:

1) развитие информационных технологий;

2) демографический тренд;

3) глобализация;

4) ускорение темпов общественного развития;

5) уход от общества потребления.

Каждый из мегатрендов порождает от одного до нескольких тенденции, которые условно можно разделить на две категории: искусственные и естественные. Искусственные тренды в своей основе имеют целенаправленное воздействие человека, обусловленное стремлением к достижению определенных целей. Естественные тренды обусловлены естественным ходом исторического развития.

Оба вида трендов в контексте рассматриваемой проблематики оказывают влияние (в виде реакции) на систему образования. Однако реакция системы образования на определенные тренды в свою очередь приводят к последующим реакциям, которые можно назвать «реакцией на реакцию».

С учетом того, что академическое предпринимательство развивается и видоизменяется, можно говорить о влиянии на эту тенденцию различных факторов. Например, о том, что тенденции в образовании влияют на развитие академического предпринимательства (табл. 1).

Рассмотрим каждый из мегатрендов подробнее. Согласно рис. 1, каждый мегатренд порождает от одного до нескольких трендов, оказывающих влияние на систему образования. Развитие информационных технологий относится к искусственным мегатрендам. На сегодняшний день прослеживаются высокие темпы развития информационных систем и технологий, детерминированные, в том числе лавинообразным увеличением объемов информации. Объем информации в мире имеет тенденцию к лавинообразному росту [11].

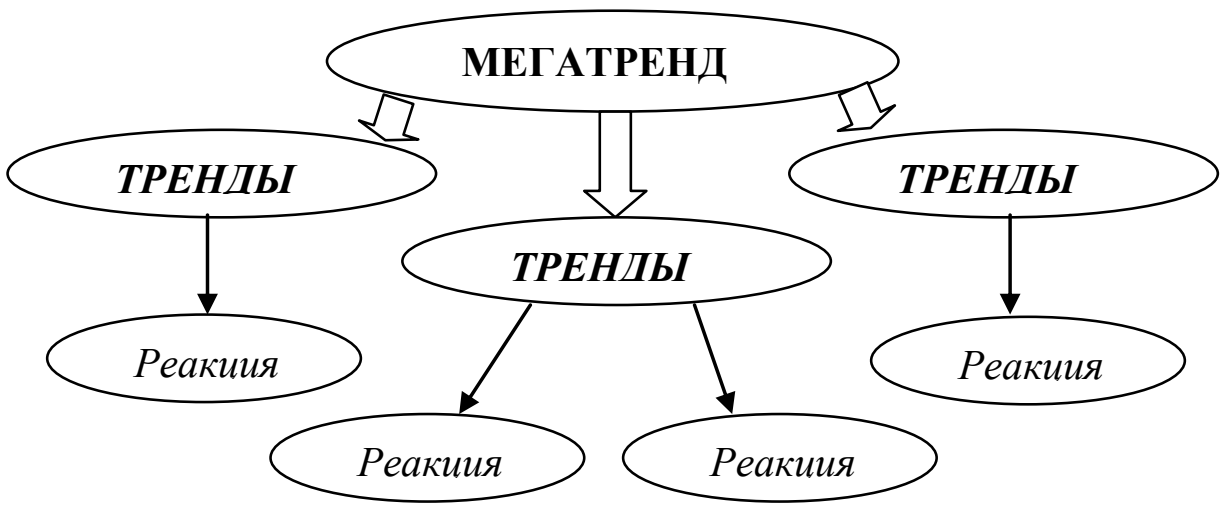

Puc. 1. Возникновение реакций системы образования на влияние трендов

Источник: составлено автором 
Влияние мегатрендов на академическое предпринимательство

Источник: составлено автором 
Мегатренд «развитие информационных технологий» является источником 2-х основных трендов:

- виртуализация в образовании (искусственный тренд), проявляющаяся в появлении и развитие новых форм и подходов к образованию, основанных на использовании современных технологий в образовании; усилении конкуренции между ВУЗами в сфере виртуального образования (дистанционного образования); появлении новых подходов к организации и осуществлению дистанционного образования; снижении качества образования;

- индивидуализация и персонификация образования (естественный тренд), проявляющаяся в популяризации технологии обучения e-learning и усилении качества подготовки студентов;

К следующему мегатренду можно отнести демографический.

Демографический мегатренд представляется как тенденция к изменению численности населения в глобальных масштабах [12]. В разных странах данная тенденция имеет разную направленность. Данный мегатренд относится к категории естественных. зис в России.

Первой тенденцией из данной категории является демографический кри-

Определяют несколько реакций системы образования на данную тенденцию.

1. Снижение численности студентов под влиянием различных факторов (демографический, повышение проходного балла и стоимости обучения, сокращение количества мест обучающихся за счет федеральных и региональных бюджетов, усиление борьбы учебных учреждений за абитуриентов, обострение конкуренции, развитие образовательных программ, направленных на обучение людей старшего поколения, развитие академической мобильности людей студенческого возраста);

2. Старение населения (демографическое старение) является результатом длительных демографических изменений, сдвигов в характере воспроизводства населения, рождаемости, смертности, их соотношения, а также частично миграции. Основной реакцией системы образования на данную тенденцию является появление необходимости в обучении людей старшего поколения новым навыкам и компетенциям, что в итоге приводит к развитию обучающих технологий и образовательных программ целевым сегментом которой являются люди старшего поколения.

Другим общественным трендом, проявляющимся в удлинении продолжительности жизни людей, ведущих активную экономическую жизнь, занятых на производстве, участвующих в экономических процессах, является увеличение продолжительности активной экономической жизни населения. Основная реакциея системы образования России на данную тенденцию - увеличение доли численности взрослых студентов по причине необходимости наработки навыков и компетенций для продолжения трудовой деятельности.

Глобализация относится к одному из мегатрендов естественного характера, проявляющегося в глобализационных процессах в сфере образования в виде тенденции к формированию единого образовательного и научного пространства на планете Земля.

Если говорить о российской системе образования, рассматриваемая тенденция нашла свое отражение в переходе на Болонскую систему обучения, введение бакалавриата и магистратуры, интеграция и интернационализация 
образования, формирующая новый рынок образовательных услуг, появление дистанционного образования. Следствием данных реакций явилось повышение затрат на обучение, снижение привлекательности приема в аспирантуру, развитие форм академической мобильности.

Ускорение темпов общественного развития выражается, в первую очередь, повышением частоты социально-экономических изменений в единицу времени. Основными факторами социальных изменений, влияющих на характер требований общества к системе современного образования, являются ускорение темпов общественного развития и бурный рост процессов информатизации $[13,14]$.

Уход от общества потребления выражается, прежде всего, тенденцией сокращения потребления материальных благ мировым сообществом и переход на новый уровень характеризующимся повышением значимости сферы услуг и смещением фокуса с потребления материальных благ в сторону потребления нематериальных. К таковым относится и получение образования. Соответственно, данный мегатренд оказывает прямое влияние на систему образования, делая ее ценность более высокой по отношению к материальным благам.

Мегатренд экономических преобразований главным образом влечет за собой изменение структуры потребления, выражающийся в смещении фокуса потребительских предпочтений с потребления материальных благ в пользу потребления нематериальных благ. Реакцией системы образования на данную тенденцию является повышение интереса в сторону потребления таких услуг как образовательные, развитие направлений в системе образования, процесс обучения в которой основывается на получении эмоции, развитие направлений образования, связанных с туризмом и сервисом.

\section{Заключение}

Вышеописанные тренды несут в себе потенциальные изменения, касающиеся всех сфер жизни, в том числе образования и, как следствие, академического предпринимательства. Углубленное изучение трендов и реакций общества на данные тренды могут позволить разработать инструменты гибкой адаптации к меняющимся условиям.

К направлениям дальнейших исследований можно отнести такие как: определение степени влияния на академическое предпринимательство реакции системы образования России на основные тенденции и тренды мировом общественном развитии, а также выявление дальнейших особенностей развития, векторов и тенденций развития академического предпринимательства, выявление факторов развития и прогнозирование результатов академического предпринимательства на ближайшую и дальнейшую перспективу.

\section{Список источников / References}

1. Полещенко К.Н., Верхогляд Е.В. Интеллектуальное предпринимательство: понятийный и образовательный аспекты. Вестник ОмГУ. 2011, №2, сс. 334-338. [Poleshhenko K.N., Verxoglyad E.V. Intellektual`noe predprinimatel`stvo: ponyatijny`j i obrazovatel`ny`j aspekty` [Intellectual entrepreneurship: conceptual and educational aspects]. Vestnik OmGU = Herald of Omsk University, 2011, no. 2, pp. 334-338.] 
2. Ашмарина С.И., Филатова А.В. Генезис понятия «Информационно-знаниевые ресурсы». Вестник СамГУ, 2012, №4 (95), сc. 11-16. [Ashmarina S.I., Filatova A.V. Genezis ponyatiya «Informacionno-znanievy'e resursy'» [Genesis of the concept of "Information and Knowledge Resources"]. Vestnik SamGU = Vestnik of Samara University, 2012, no. 4 (95), pp. 11-16.]

3. Abreu M. The nature of academic entrepreneurship in the UK: Widening the focus on entrepreneurial activities. Research Policy, 2013, vol. 42, pp. 408-422.

4. Fairchild R. An entrepreneur's choice of venture capitalist or angel-financing: a behavioral game-theoretic approach. Journal of Business Venturing, 2014, vol. 26, pp. 359-374.

5. Nabi G. From student to entrepreneur: towards a model of graduate entrepreneurial career-making. Journal of Education and Work, 2010, vol. 3, pp. 22-38.

6. Zhang J. Why do some US universities generate more venture-backed academic entrepreneurs than others? Venture Capital, 2009, vol. 11, pp. 133-162.

7. Wood M.S. A process model of academic entrepreneurship. Business Horizons, 2011, no. 54, pp. 153-161.

8. Abreu M., Grinevich V. The nature of academic entrepreneurship in the UK: Widening the focus on entrepreneurial activities. Research Policy, 2013, vol. 42, pp. 408-422.

9. Weckowska D.M. Learning in university technology transfer offices: transactions-focused and relations-focused approaches to commercialization of academic research. Technovation, 2015, vol. 41, pp. 62-74.

10. Mindeli L. The main directions of the innovation potential of scientific institutions of RAS. Innovation, 2013, vol. 11, pp. 33-39.

11. Sikula A.F. The professor as an artist, a scientist, and an entrepreneur. The Teacher Educator, 2010, vol. 3, pp. 23-44.

12. Хазиев Р.Р. Прогнозирование демографической ситуации в Российской Федерации. Символ науки, 2015, №12-1, сc. 47-62. [Xaziev R.R. Prognozirovanie demograficheskoj situacii v Rossijskoj Federacii [Forecasting the demographic situation in the Russian Federation]. Simvol nauki $=$ Symbol of science, 2015, no. 12-1, pp. 47-62.]

13. Электронный научно-образовательный журнал ВГСПУ «Грани познания». Декабрь, 2013, №7 (27). [E`lektronny`j nauchno-obrazovatel`ny`j zhurnal VGSPU «Grani poznaniya» [Electronic scientific and educational journal of VGSPU "Faces of knowledge"]. December 2015, no. 7 (27). Available at: www.grani.vspu.ru

14. Хасаев Г.Р., Ашмарина С.И. Основные тренды развития и перспективы повышения конкурентоспособности системы высшего образования. Вестник Самарского государственного экономического университета, 2014, №8 (118), сc. 62-65. [Xasaev G.R., Ashmarina S.I. Osnovny`e trendy` razvitiya i perspektivy` povy`sheniya konkurentosposobnosti sistemy` vy`sshego obrazovaniya [The main development trends and prospects for increasing the competitiveness of the higher education system]. Vestnik Samarskogo gosudarstvennogo e konomicheskogo universiteta $=$ Bulletin of Samara State University of Economics, 2014, no. 8 (118), pp. 62-65.]

\section{Сведения об авторе / About author}

Измайлов Айрат Маратович, кандидат экономических наук, доцент кафедры прикладного менеджмента, Самарский государственный экономический университет. 443090 Россия, г. Самара, ул. Советской Армии, 141.E-mail: airick73@bk.ru

Ayrat M. Izmailov, Candidate of Economics Sciences, Associate Professor of the Department of Applied Management, Samara State Economic University. 141 Sovetskoi Armii Street, Samara, Russia 443090.E-mail: airick73@bk.ru 